\title{
Monetary and fiscal policy coordination and macroeconomic stabilization. A theoretical analysis ${ }^{1}$
}

\author{
Luca Lambertini Riccardo Rovelli \\ Dipartimento di Scienze Economiche \\ Università di Bologna
}

February 14, 2003

\footnotetext{
${ }^{1}$ A first version of this paper has been presented at seminars at the ASSA meetings (Washington D.C., 2003) and at Igier (Milano, 2003). We thank several participants for comments, and in particular Alberto Alesina, Luca Sala and Guido Tabellini. Thanks also to Alessandro Missale for comments on an earlier draft. All errors are our own.
} 


\begin{abstract}
We examine the relations between monetary and fiscal policies in the process of macroeconomic stabilization. Our model suggests that each policy maker prefers to be the second mover in a "Stackelberg" situation, i.e. where one policy makers precommits its policy choice. At the same time, both Stackelberg solutions are preferable, for each policymaker, to the Nash solution. We argue that there is a natural way to choose among the two Stackelberg games. This solution implies that the government acts as a leader and sets fiscal policy according to the minimization of a Social Welfare Function (which fully internalizes also the objective of price stability). This optimal solution mirrors existing institutional arrangements, where fiscal policy decisions are typically taken before, and less frequently than monetary policy decisions.

We interpret our results in relation to the debate on monetary-fiscal coordination in EMU and on the role of the Stability and Growth Pact. We argue that a coordination mechanism along the lines of the Broad Economic Policy Guidelines is desirable.
\end{abstract}

Keywords: Monetary Policy, Fiscal Policy, Policy Coordination, EMU, Stability and Growth Pact.

JEL codes: E520, E610, E630, H700. 


\section{Introduction}

A widely shared conventional wisdom holds that policymakers should not engage in excessive attempts to "fine-tune" the economy. Hostility towards fine-tuning is partly explained by the notion that the variances of output or inflation around their targeted or natural levels cannot be entirely eliminated. However, this does not imply that stabilization policies should be altogether avoided. As Alan Blinder remarked, "doesn't even a poor archer aim for the bull's-eye, even though he doesn't expect to hit it?" (1997, p.12). In fact, precisely for this reason the recent literature on central bank policies has focused on how to design monetary institutions in a way that induces central bankers to aim for a low average inflation rate, while at the same time preserving enough flexibility to respond to unforeseen circumstances (see e.g. Rogoff, 1987; Persson and Tabellini, 1993; Walsh, 1995).

This literature typically assumes that monetary authorities are the only policymakers possibly concerned with output stabilization. On the other hand, it is also well known that, "in an economy in which fluctuations are partly due to the combination of aggregate demand effects and nominal rigidities, fiscal policy also [in addition to monetary policy] has the potential to reduce fluctuations in aggregate demand" (Blanchard and Fischer, 1989, p. 583). In this paper we elaborate on this fact, to dispute the notion that only monetary authorities should be concerned with stabilization, or that different authorities should pursue their own policies without explicitly acknowledging the others'. In particular, we argue that while monetary and fiscal authorities may differ in their motivations and ultimate goals, their policy choices have a decisive impact, inter alia, on the same variable: aggregate demand. This is of immediate concern for both policymakers, no matter whether they consider aggregate demand (or the output gap) as an argument in their objective function (as will be generally the case for fiscal authorities) or only as an intermediate variable in the policy-transmission mechanism (as would be the exclusive concern of an inflation nutter-type central banker).

As a consequence, we argue that it would be advisable for both authorities, and generally welfare-improving, to achieve some form of coordination between them. At this stage, "coordination" may be taken to mean any of the following situations: (i) exchange of information between policymakers; (ii) mutual acknowledgement of the existence and probable behavior of the other policy maker; (iii) joint-decision making between policymaker (full cooperation, i.e. collusion); (iv) agreement on a sequence of moves between the two 
authorities. State (i) is compatible with either of the other three states. Situation (ii) would probably result in the selection of an equilibrium, consistent with each policy maker being on its best reply function, whereas situation (iv) is equivalent with identifying one of the two policy makers as the leader, and the other as the follower. We may ask what happens in case of failure to achieve some kind of coordination, even of the weakest type. In this case, the independent decisions of monetary and fiscal authorities will either result in a duplication of efforts or, when they are setting their instruments in opposite directions, negative externalities.

Before we move on to a formal anlysis, we may gain an intuitive understanding by considering the following example. Imagine a typical budgeting session, which takes place sometime in the course of year 00 , where the stance of fiscal policy for year 01 is being discussed. Suppose a negative demand shock is foreseen for that year, while inflation is expected to stay at the targeted level of $2 \%$. Policymakers are thus faced with the choice between the following options: (a) do nothing, let the automatic stabilizers work, with the perspective that monetary policy would be set on a moderately expansive path. In this case, we will then observe a "moderate" fiscal deficit (let us say, $2 \%$ of gdp), and low interest rates (say, $3 \%$ in nominal terms); (b) neutralize the fiscal stabilizers, hence hold the deficit close to balance, and expect a more expansive monetary policy, e.g. nominal interest rates at $1.5 \%$; (c) decide upon a more aggressive fiscal stance, resulting in a deficit of, say, $3.5 \%$, but with the expectation that monetary policy would then be set on a mildly restrictive tone, with nominal interest rates at $4 \%$. Even if we assume, for the sake of the argument, that these three choices result in the same degree of output stabilization and inflation outcome, they will not in general be equivalent, as the policy outcomes $(2 ; 3),(0 ; 1.5)$ and $(3.5 ; 4)^{1}$ could in principle be ranked on a welfare scale.

One might observe that in many or perhaps in most countries, as for instance in the USA, such a debate rarely seems to take place. This however does not mean that policy makers do not take each other's actions into account. On the contrary, this simply implies that in most countries option (a) is the default choice during a moderate recession, and need not be reassessed at each time. Only an exceptional cyclical outcome requires an additional debate. As a consequence of one such debate, in the course of $2001,{ }^{2}$ it was

\footnotetext{
${ }^{1}$ The first number refers to the fiscal deficit and the second to the nominal rate of interest.

${ }^{2}$ For instance, in January 2001 FRB Chairman Alan Greenspan observed "Lately there
} 
decided to adopt an aggressive discretionary fiscal policy for 2002.

On the other side of the Atlantic, in the EU, the debate is quite active, essentially because fiscal policy is set by the individual member states, while monetary policy has been centralized, at least for those countries, which have adhered to EMU. Decentralization of fiscal policies has brought to the forefront a debate about the need for (fiscal) policy coordination, which in turn has produced the adoption of quite complicated, and possibly ineffectual, rules and procedures to avoid excessive deficits and ensure the sustainability of national debts. ${ }^{3}$ On these issues the official position of the European Commission, the European Council and the European Central Bank (ECB) that is, of all those institutions, which have been designed to discuss policies with an aggregate, union-wide perspective - can be described in terms similar to option (a). ${ }^{4}$ On the other hand, the rules embodied in the Stability and

has been much discussion of cutting taxes to confront the evident pronounced weakening in recent economic performance. Such tax initiatives, however, historically have proved difficult to implement in the time frame in which recessions have developed and ended. For example, although President Ford proposed in January of 1975 that withholding rates be reduced, this easiest of tax changes was not implemented until May, when the recession was officially over and the recovery was gathering force. Of course, had that recession lingered through the rest of 1975 and beyond, the tax cuts would certainly have been helpful. In today's context, where tax reduction appears required in any event over the next several years to assist in forestalling the accumulation of private assets, starting that process sooner rather than later likely would help smooth the transition to longer-term fiscal balance. And should current economic weakness spread beyond what now appears likely, having a tax cut in place may, in fact, do noticeable good." (Testimony Before the Committee on the Budget, U.S. Senate, 25 January 2001, http://www.federalreserve.gov/boarddocs/testimony/2001/, emphas is added.). As the economic situation deteriorated further after the events of September 11, also Greenspan was persuaded that a more expansive discretionary fiscal stance would be appropriate.

${ }^{3}$ See e.g. the critical review of the current procedures by von Hagen and Mundschenk (2001). Recently, the European Commission (2002b) has put forward some proposals to improve the application of existing rules.

${ }^{4}$ The emphasis placed by European Commission on the role of automatic fiscal stabilizers for the functioning of the Stability and Growth Pact (see Brunila, Buti and in 'tVeld, 2002, and European Commission, 2002a) should be interpeted as a signal of their strong preference for option ( $a$ ), as described in the text.

Moreover, it is also clear that all three institutions mentioned in the text clearly perceive the externalities which each policy generates on the other. We mention here three examples. The first two are relative to the European Council: "Budgetary policies should continue to be geared to the achievement of public finances close to balance or in surplus, so as to support the price-stability orientation of monetary policy, and thereby to foster continued economic growth and employment creation." (Issue paper on the Broad 
Growth Pact imply - if taken literally - that automatic stabilizers should not be allowed to operate for those countries with a high initial debt, or which are starting off with deficits close to $3 \%$. Hence, existing rules would force these countries towards option (b). In addition countries, like France and Germany, which would like to unilaterally adopt more expansionary fiscal policies, even at the cost of being sanctioned by the EU institutions ${ }^{5}$, are in fact advocating option (c).

In this paper, we develop a formal analysis to support the idea that coordination of fiscal and monetary policy is beneficial to ensure a smooth performance of monetary policy - that is, to minimize the costs of price stability. Our view complements the recent but well-established opinion in monetary economics, which has forcefully argued in favor of central bank independence (CBI). Within this tradition, an "indisciplined" fiscal policy is a strong challange to CBI, as it might force the central bank to give up its independence and monetize the debt ${ }^{6}$. Our argument is that even when fiscal policy is perfectly sustainable (in the long run) it may still undermine the policy stance adopted by the monetary authority.

What kind of coordination does our model suggest would be desirable? Leaving the formal analysis to be developed below, we may notice that in practice, there is a natural solution to this question: the policy process un-

Economic Policy Guidelines 2001, March 2001). "The budget for 2001 will give a further substantial boost to demand in Ireland and its possible supply effects are likely to be small in the short term. It will therefore aggravate overheating and inflationary pressures and widen the positive output gap." (Recommendation of 26/02/2001 on fiscal policy in Ireland: http://ue.eu.int/emu/convergence/irl/IR-RECOMMENDATION2001.pdf). The third example is from the ECB, and clearly shows how the central bank believes that also fiscal policy is, at least in the short run, responsible for inflationary pressures: "The expansionary fuscal policies planned for this year [2001] in a number of euro area countries are not conducive to containing aggregate demand and inflationary pressures. Particularly in the countries experiencing high economic growth rates, inflationary pressures will receive an additional stimulus from expansionary fuscal policies" (ECB Annual Report 2000, May 2001, p. 47).

${ }^{5}$ On January 21, 2003, the Ecofin meeting of EU finance ministers started the "excessive deficit procedure" against Germany, and approved an "early warning" to France. Both measures were taken following a proposal from the EU Commission.

${ }^{6}$ There are two rather different versions of this argument: the unpleasant monetarist arithmetics of Sargent and Wallace (1981), and the fiscal theory of the price level of Leeper (1991) and Woodford (1995, 1998). In the first approach, CBI is challenged by fiscal authorities, which play the role of a Stackelberg leader against the central bank. In the second approach, instead, CBI becomes irrelevant, since the price level adjusts independently of the policy actions decided by the central bank. 
derlying fiscal decisions is by "nature" lenghty and complex, and cannot be easily reverted once decisions reach the stage of implementation; on the contrary, the institutional process underlying monetary policy decisions can be implemented in a very short time ${ }^{7}$, and easily reverted. Hence, fiscal authorities would naturally behave as leaders in a strategy game with central bankers. One feature of our analysis, as we show below, is that this arrangement is shown to be desirable even before we take into account these institutional features.

The paper is organized as follows. Section 2 briefly reviews the relevant literature. Section 3 sets up the basic model of the economy. Section 4 analyzes the interaction of fiscal and monetary policy in a Nash equilibrium. Sections 5 and 6 analyze Stackelberg equilibria, with the central bank acting respectively as a follower and as a leader. Naturally, the outcome of the game will be different, in each of these three sections. In section 7 we propose a simple and natural criterion to choose among the different equilibria. Section 8 concludes.

\section{Review of the literature}

If monetary policy is committed to price stability, why should monetary and fiscal policies coordinate? In this paper we suggest a straight answer to this question. However, our approach is somewhat innovative in the context of the recent literature. Analyzing this literature, we may identify at least five different approaches ${ }^{8}$. First, the literature on the monetary implications of fiscal (in)discipline, which originates with Sargent and Wallace (1981), emphasizes that, to the extent that the path of a government's fiscal deficit is predetermined and unsustainable, then monetary policy and the price level are no longer exogenous to it. A similar point arises in the context of the Fiscal Theory of the Price Level (Leeper, 1991, and Woodford, 1995). However, in these frameworks the goals of fiscal policy are not explicitly discussed, and

\footnotetext{
${ }^{7}$ Typically, monetary policy decisions are taken every two weeks both in the US and in the euro area.

${ }^{8} \mathrm{~A}$ general survey of these issues in neoclassical models is in Chari and Kehoe (1999). Issues of coordination also appear in models of the optimal inflation tax or seigniorage policy (Barro, 1979; Lucas and Stokey, 1983). In particular, Alesina and Tabellini (1987) study the desirability of fiscal and monetary policy coordination in a seigniorage model where monetary policy has no stabilization features and (expansive) fiscal policies affects output negatively.
} 
do not include macro stabilization. Nevertheless, the scenario analyzed by Sargent and Wallace has surely been influential in motivating the emphasis on fiscal discipline as a pre-requisite for monetary stability, which has been placed in the Treaty of Maastricht and, in particular, on the design of the criteria for admission to the third phase of EMU.

A different question is examined in a second strand of literature. Beetsma and Bovenberg (1999 and 2001) examine the case where the existence of a more inflation-averse central bank is shown to have a perverse effect on the incentive of fiscal authorities to reduce debt levels.

Other papers do not share the assumption that policy makers are effectively committed. In a third strand of literature, Beetsma and Uhlig (1999) observe that a distortionary fiscal policy will induce a wedge between actual and natural output, thus tempting the central bank (which would like to stabilize output around its natural level) into adopting (time inconsistent) inflationary policies ${ }^{9}$. In a similar vein, Dixit and Luisa Lambertini (2001; 2002) assume that both fiscal and monetary authorities follow time- and mutuallyinconsistent rules, and discuss how different coordination mechanisms may or may not alleviate the undesirable consequences of non-coordinated behavior. In their model fiscal policies affect output and inflation in different directions, contrary to the standard result generally assumed in the literature and to the evidence reported in Fatas and Mihov (2001). In particular Dixit and Luisa Lambertini (2002) model a race between the two policies, assuming that the output and inflation targets of the central bank are both set below the targets values of fiscal authorities. At the end of the game, monetary policy is too contractionary and fiscal policy not expansionary enough. In this case, with (discretionary) fiscal policy being chosen strategically, the reaction function of the fiscal authority acts as a constraint on the monetary rule, and this effectively negates the advantage of monetary commitment. The conclusion of their analysis is that, without a time-consistency problem, both the monetary and the fiscal authority should have identical output and price goals that coincide with the socially optimal ones. With a time-consistency problem, the inflation obiective should be lowered, but it is crucial that the output and inflation objectives of the two authorities should be the same.

The existence of decentralized fiscal authorities is analyzed in a fourth group of papers. The main differences between these papers is in the assump-

\footnotetext{
${ }^{9} \mathrm{~A}$ similar issue was raised by Debelle and Fischer (1995) in the context of a model where the central bank did not accept the natural level of output as its ultimate goal.
} 
tions about the objective functions of the different authorities. Beetsma and Bovenberg (2001) analyze the case when both monetary and fiscal authorities are unable to commit to their policy targets and nominal wages are predetermined. They study under what conditions this leads to a "wasteful strategic accumulation of government debt". In particular they argue that, in the absence of an explicit commitment by fiscal authorities, ex-post coordination at the fiscal level may actually be harmful. A similar result emerges in a related paper by Beetsma, Debrun and Klaassen (2001). Andersen (2002) finds that the costs of non-cooperative fiscal policies tend to be large in the case of aggregate (symmetric) shocks, and increase with the number of policy actors; on the contrary, these costs are small in the case of idiosyncratic shocks, and decreasing in the number of actors. Uhlig (2002) assumes that the central bank is motivated by the desire to minimize deviations of output from its natural level and of inflation from its target. In this case, adding a number of fiscal authorities essentially concerned only with ouput may result in inefficiencies, as there will be an aggregate pressure to stabilize output, which will have inflationary implications and thus induce the central bank to raise interest rates. In his model, differently from ours (see next section) the central bank attaches no cost to the level of interest rates. Hence in equilibrium an excessive fiscal expansion will have no consequences either on output or on inflation. In this case, however, coordination by fiscal authorities would be beneficial, in the limited sense that it will help to keep interest rates down.

Finally, a fifth approach assumes that the main source of interaction between the two policies originates from the fact that they both similarly affect aggregate demand and inflation. Hence fiscal policy matters for its impact on aggregate demand, while the issue of debt accumulation if neglected (as fiscal deficits average to zero over time, consistently with the requirements of EMU under the SGP). Also, in this strand of literature, the central bank is assumed to act in a time-consistent fashion, following an objective function formalized in accord to the mandate assigned to the ECB. Buti, Roeger and in't Veld (2001) analyze in this vein the interaction of monetary and fiscal policies. Assuming that fiscal authorities do not care for inflation, they find that cooperation is desirable, in particular when the economies are hit by a supply shock. In a related, more general framework van Aarle, Engwerda and Plasmans (2001) analyze two countries, with decentralized fiscal authorities and a centralized monetary authority. Their basic framework is similar to the one which we adopt below. They analyze - by numerical simulations 
- the equilibrium strategies which arise in continuous time over an infinite horizon. The cases they consider include: non cooperation between the three authorities; full cooperation; coalition between the two fiscal authorities only; coalition between one fiscal authority and the monetary authority. These setups are examined under both assumptions of symmetry and asymmetry between the two countries involved. Their main finding is that cooperation is efficient for fiscal authorities, since a common stance against the ECB produces a Pareto improvement. This may not hold at the equilibrium of the fully cooperative (that is, including the ECB) game. In Luca Lambertini and Rovelli (2003) we also show analytically that there are gains if the two authorities cooperate, in the sense that fiscal policy should be set taking into account a welfare function defined over both output and inflation stabilization, the latter defined consistently with the ECB. The main difference with this framework, which we have introduced in the present paper, is that here we analyze at some length the strategic interaction of the two policymakers.

\section{The model}

We analyze a simple model of a closed economy, which is the static equivalent of a conventional aggregate demand / aggregate suppy model, with short run price rigidity. ${ }^{10}$ In the short run, we may observe a positive value of the output gap $\left(y>y^{*}\right)$ following either an expansionary monetary policy (which temporarily lowers the short run real rate of interest $\left(i-\pi^{*}\right)$ below the long run equilibrium value, $\bar{r}$, or an expansionary fiscal policy $(f>0)$ or an unexpected positive demand shock, $\varepsilon_{1}$.

$$
\mathrm{AD}: y=y^{*}-\alpha\left(i-\pi^{*}-\bar{r}\right)+\eta f+\varepsilon_{1}
$$

Inflation, $\pi$, will increase/decrease relative to the target level, $\pi^{*}$ (which, in the absence of shocks, is also its expected value), in response to positive/negative values of the output gap, and also to unexpected supply shocks $\varepsilon_{2}$ :

$$
\text { AS }: \pi=\pi^{*}+\beta\left(y-y^{*}\right)+\varepsilon_{2}
$$

We assume that $\varepsilon_{1}$ and $\varepsilon_{2}$ are i.i.d. with zero mean and constant variance and they are observed in real time only by policy makers. In this case, we

\footnotetext{
${ }^{10}$ See e.g. Svensson (1997)
} 
note that the inclusion of an additional term describing inflationary surprises for the general public $(\pi-E(\pi))$ in the AS would not influence any results since $E(\pi)=\pi^{*}$ always.

Also note that $\alpha, \beta, \eta$ are positive parameters and that the shocks $\varepsilon_{i}, i=$ 1, 2 are i.i.d, and we assume below that both fiscal and monetary policy can be set optimally with no lag, in response to realized values of the two shocks.

We define the following policy problem. We assume that, given the available resources, social welfare is maximum when, in the absence of shocks, $y=y^{*}$ and $\pi=\pi^{*}$. In this cases it is then optimal to adopt a neutral policy stance, that is $i=\bar{r}+\pi^{*}$ and $f=0$. When shocks occur, then the economy is temporarily driven away from the social optimum, and both fiscal and monetary policy may adopt a non-neutral stance.

We also assume that there is positive, convex social cost associated to the use of either policy instrument. The existence of a cost associated to changes in the real interest rate is conventionally embodied in many models of monetary policy, and also documented empirically ${ }^{11}$. As regards fiscal policy, this assumption reflects two facts: (i) a higher level of fiscal expansion implies a higher crowding out of private expenditures, and this is perceived to be costly; (ii) in the EU, the Stability Pact requires that the fiscal stance is on average neutral $(f=0)$, so that departures from a balanced budget should only be small and temporary ${ }^{12}$. We thus postulate the following quadratic social loss function, which defines the preferences of society, and hence also of the government:

$$
L_{S} \equiv\left(\pi-\pi^{*}\right)^{2}+\mu(r-\bar{r})^{2}+\left(y-y^{*}\right)^{2}+\gamma f^{2}
$$

Note that this formulation of the social loss function assumes that the output and inflation terms share the same weight. While this is arbitrary (but not irrealistic), it avoids introducing an additional weighting parameter. It will become clear below that no qualitative result depends critically on this assumption. In addition, we assume that $\mu, \gamma$ are positive parameters.

\footnotetext{
${ }^{11}$ For instance, Walsh $(1998$, ch.10) argues why the central bank might attach a positive value to interest rate smoothing. Empirically, this choice is motivated by the desire to account for the observed persistence or graduality in the setting of the Federal Funds rate. See Favero and Rovelli (2003).

${ }^{12}$ This assumption also implies that there will not be a sequence of government deficits, potentially generating an excessive accumulation of government debt, such as to pose a threat to the independence of monetary policy, as in Sargent and Wallace (1981).
} 
Now we need to define the institutional setup for policy decisions, which mimics the one adopted in the Euro-area (and also in all countries which have set up and independent central bank) We assume that the central bank is independent of the government and commited to inflation stabilization. Hence, the government delegates to it the following subset of $L_{S}$.

$$
L_{M} \equiv\left(\pi-\pi^{*}\right)^{2}+\mu(r-\bar{r})^{2}
$$

The reason why the loss function $L_{M}$ is assigned to the central bank may be rationalised as follows. Assume alternatively that the central bank's loss function also included a term accounting for output stabilisation. In this case, optimal monetary policy would be time-inconsistent vis à vis the government's fiscal stance, in the same sense as it would be time-inconsistent against the private sector in a model à la Kydland and Prescott (1977) or Barro and Gordon (1983). We formalize this point in the Appendix. If the central bank were not bound by contract to minimize a specific loss function, it could be driven to announce a time inconsistent policy so as to generate inflation in excess of $\pi^{*}$, in order to increase $y$. If the government is rational and fully informed, but the central bank takes the fiscal stance as given, then the monetary policy is going to be time-inconsistent.

As regards fiscal policy, the government delegates it to an authority (which we shall refer to as "the treasury"), which is empowered with the setting of the fiscal stance, but is not independent of the government. ${ }^{13}$ How should the objective function of the treasury be optimally specified? A priori, the answer is not clear, and surprisingly this question does not seem to have been previously addressed. In principle, there are two alternatives, or benchmark solutions: either, given that the control of inflation has been assigned to the central bank, the treasury is assigned responsibility only for the management of $\mathrm{AD}$ via the fiscal stance, or the government imposes to the treasury to act in accord with its general objective function. To the extent that bureacracies tend to live a life of their own, the treasury will be posing pressure to focus only on the management of $\mathrm{AD}$ (also, perhaps, in response to public or trade union pressures). In any case, if the treasury looks only at $\mathrm{AD}$ and at the cost of setting its fiscal stance differet from zero, then it will minimize:

\footnotetext{
${ }^{13}$ In a related paper (Lambertini and Rovelli, 2002), we also study the optimal design of fiscal policy as a linear convex combination of price and output stabilisation, given central bank independence.
} 


$$
L_{F} \equiv\left(y-y^{*}\right)^{2}+\gamma f^{2}
$$

Finally, note that, given $(4-5)$, the social loss function may be simply defined as the sum of the two sub-functions:

$$
L_{S} \equiv L_{F}+L_{M}
$$

In the following sections, we shall be explicitly concerned with the following two questions: (1) given that the central bank has been set up with an independent mandate, which is the desirable sequence of decisions between the setting of monetary and fiscal policies? (2) given that the government is concerned with the minimization of $L_{S}$, subject to the independence of the central bank, should it run fiscal policy according to the minimization of $L_{S}$ (the "Government view") or should it instead run it according to the "Treasury view", that is to the minimization of $L_{F}$ only?

Now we derive the optimal policy functions of the two authorities. Given our static setup, we cannot write them down as Taylor rules, since this could be done only if we assumed that $y$ and $\pi$ were predetermined. We thus write each authority's best reply function, obtained by optimizing their respective loss functions subject to the constraints (1-2) and assuming as given the choice of the other authority:

$$
\text { Central bank: } \quad i^{b r}=\bar{r}+\pi^{*}+\frac{\alpha \beta}{\alpha^{2} \beta^{2}+\mu}\left[\beta\left(\eta f+\varepsilon_{1}\right)+\varepsilon_{2}\right]
$$

Fiscal authority using $L_{F}: \quad f^{b r}=\frac{\eta}{\eta^{2}+\gamma}\left[\alpha\left(i-\pi^{*}-\bar{r}\right)-\varepsilon_{1}\right]$

Fiscal authority using $L_{S}: \quad f^{b r}=\frac{\alpha \eta\left(1+\beta^{2}\right)\left(i-\pi^{*}-\bar{r}\right)-\eta\left[\left(1+\beta^{2}\right) \varepsilon_{1}+\beta \varepsilon_{2}\right]}{\gamma+\eta^{2}\left(1+\beta^{2}\right)}$

where superscript $b r$ stands for best reply function.

Note that, as it should be expected, each authority maneuvers its policy instrument in a restrictive way (higher $i$, lower $f$ ) in response to any expansionary $(>0)$ shock to aggregate demand (AD: $\left.\varepsilon_{1}\right)$ or supply (AS: $\varepsilon_{2}$ ). Moreover, best replies are everywhere increasing, irrespective of the values taken by the vector of shocks. In particular, the slope of the reaction function 
of the central bank w.r.t. the fiscal stance $f$ is:

$$
\frac{\partial i^{b r}}{\partial f}=\frac{\alpha \beta^{2} \eta}{\alpha^{2} \beta^{2}+\mu}
$$

If the treasury sets $f$ so as to minimise $L_{F}$, the slope of the best reply function is:

$$
\frac{\partial f^{b r}}{\partial i}=\frac{\alpha \eta}{\eta^{2}+\gamma}
$$

while if the government sets $f$ so as to minimise the social loss $L_{F}$, the slope is: ${ }^{14}$

$$
\frac{\partial f^{b r}}{\partial i}=\frac{\alpha \eta\left(1+\beta^{2}\right)}{\gamma+\eta^{2}\left(1+\beta^{2}\right)}
$$

with

$$
\frac{\alpha \eta\left(1+\beta^{2}\right)}{\gamma+\eta^{2}\left(1+\beta^{2}\right)}>\frac{\alpha \eta}{\eta^{2}+\gamma}
$$

for all $\beta>0$. Therefore:

Lemma 1 Provided that the weight of the output gap in the AS curve is positive, the best reply function of the government is steeper than the best reply function of the treasury.

When the government directly manages the budget with the aim of maximising social welfare, the optimal reaction to a given change in the interest rate is, in general, higher than it would be if the treasury controlled the fiscal instrument, as in the former case the government gets a further boost by internalising the target of price stability.

Mapping the indifference curves of the fiscal and monetary authorities and drawing accordingly their best reply functions in the space $\{f, i\}$, we can fully characterise their preferences over the timing of moves. That is, we can tell whether they will non-cooperatively choose to play a Nash or a Stackelberg equilibrium, according to the rules of an 'extended game' as defined by d'Aspremont and Gérard-Varet (1980) and Hamilton and Slutsky (1990). ${ }^{15}$ The structure of the extended game is as follows. Before choosing

\footnotetext{
${ }^{14}$ Therefore, the nominal interest rate and the fiscal stance are strategic complements (Bulow, Geanakoplos and Klemperer, 1985).

${ }^{15}$ The same toolbox is applied to the problem of the international coordination of monetary policies in Lambertini (1999), using the same model as in Hamada (1976) and Canzoneri and Henderson (1991), inter alia.
} 
optimally the levels of $f$ and $i$, the fiscal authority (i.e., the government or the treasury) and the central bank have to play a preliminary stage (the so-called preplay stage) where they have to decide non-cooperatively and simultaneously the order of moves which will be adhered to at the following stage. Assume that there are two instants, $t_{1}$ and $t_{2}$, at which the two authorities can move. These instants are purely logical entities, and do not belong to calendar time; they represent the pure strategies available to players at the first (preplay) stage. Accordingly, there is no discounting. If both players declare that they want to move at the same instant, either $t_{1}$ or $t_{2}$, then the relevant equilibrium concept for solution of the second stage is the Nash equilibrium. Otherwise, if one player chooses $t_{1}$ while the other chooses $t_{2}$, the relevant solution concept for the ensuing stage is going to be a Stackelberg equilibrium, with the player that has chosen $t_{1}$ as the leader.

Hence, the extended game is a two-stage game where the first stage concerns the choice of timing; while the second stage is the proper policy game where policy instruments are to be set according to the sequence selected at the previous stage. The solution concept for the tw-stage game is the subgame perfect equilibrium by backward induction.

Now observe figure 1, where, as an example, we have drawn the isoloss curves and the best reply functions of the central bank and the government (the graph would be qualitatively equivalent in the case where the treasury controls $f$ ). As highlighted above, the reaction functions are everywhere increasing. Moreover, the loss suffered by each player decreases as we depart from the origin, with the bliss points of both authorities locating to the North-East of the intersection of best replies, which identifies the Nash equilibrium (point $N$ ). ${ }^{16}$ For the sake of simplicity, figure 1 describes only one of the two possible Stackelberg equilibria, namely, that where the leader's role is assumed by the government (point $g$ ). In such equilibrium, both players are better off than in the Nash equilibrium. The same property would emerge in the Stackelberg equilibrium where the bank leads. This entails that, given rational expectations concerning the shocks, both Stackelberg equilibria Pareto-dominate the Nash equilibrium. That is, if players have to non-cooperatively choose the timing of moves on the basis of the expected values of their respective loss functions, then they will surely de-

\footnotetext{
${ }^{16}$ The fact that best reply functions intersect in the positive quadrant is obviously arbitrary, since there are infinitely many values of the two shocks such that the optimal fiscal stance may take negative values.
} 
sire to avoid playing simultaneously. Once they have declared to be willing to move sequentially, neither of the players has any incentive to renege ex post, and therefore sequential play is part of a subgame perfect equilibrium. Equivalently, announcements are strictly adhered to by both players, and the resulting equilibrium behaviour is time consistent.

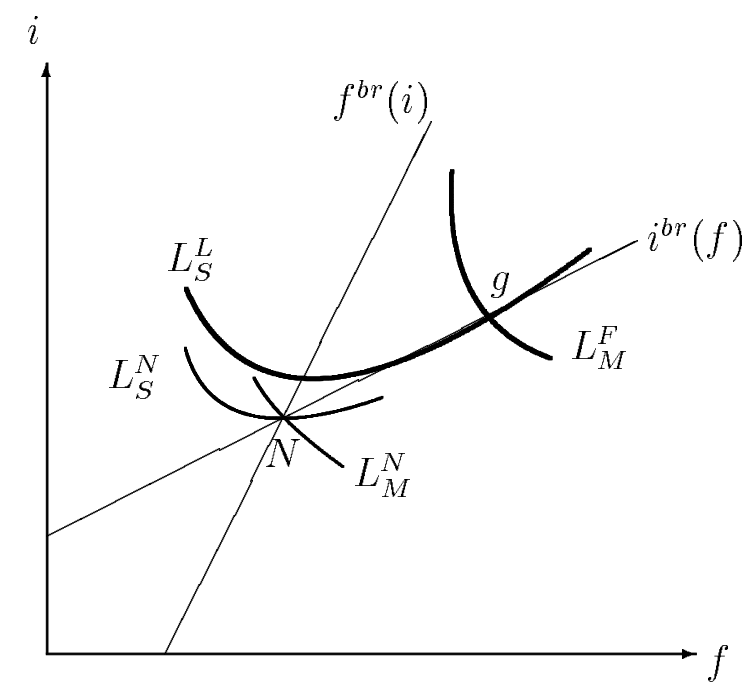

Figure 1 : Isoloss curves and reaction functions

In line of principle, the Pareto-dominance of both Stackelberg equilibria (i) does not necessarily entail that the policy game will be played sequentially instead of simultaneously, and (ii) does not solve the coordination problem. Issue (i) arises precisely because players must choose simultaneously and non-cooperatively the respective timing, involving a positive probability that simultaneous play be observed at the mixed strategy equilibrium. Issue (ii) relates to the fact that there are two Pareto-dominant Stackelberg equilibria, so that a problem of multiplicity exists a priori. As we shall prove in the remainder of the paper, the present model allows us to answer both questions by selecting one of the two Stackelberg equilibria, as the 'natural' solution of the game. 


\section{Monetary and fiscal policy coordination as a Nash equilibrium}

Now we examine the case where the two authorities set their respective instruments $(i, f)$ simultaneously and compute the resulting Nash equilibria.In this section, we consider a single country, and evaluate the government's incentive to use $L_{S}$ or $L_{F}$. Notice that in all what follows, in order to economize on notation, we redefine:

$$
\bar{r}+\pi^{*}=\pi^{*}
$$

\subsection{Case I: The treasury sets $f$ to minimise $L_{F}$}

Here, we consider the equilibrium policy setting obtained at the intersection of $(7-8):{ }^{17}$

$$
\begin{gathered}
f^{N F}=\frac{\eta\left(\alpha^{2} \beta \varepsilon_{2}-\mu \varepsilon_{1}\right)}{\alpha^{2} \beta^{2} \gamma+\left(\eta^{2}+\gamma\right) \mu} \\
i^{N F}=\pi^{*}+\frac{\alpha \beta\left(\left(\eta^{2}+\gamma\right) \varepsilon_{2}+\beta \gamma \varepsilon_{1}\right)}{\alpha^{2} \beta^{2} \gamma+\left(\eta^{2}+\gamma\right) \mu}
\end{gathered}
$$

yielding the following equilibrium losses:

$$
\begin{gathered}
L_{F}^{F}=\frac{\gamma\left(\gamma+\eta^{2}\right)\left(\mu \varepsilon_{1}-\alpha^{2} \beta \varepsilon_{2}\right)}{\left[\alpha^{2} \beta^{2} \gamma+\left(\eta^{2}+\gamma\right) \mu\right]^{2}} \\
L_{M}^{F}=\frac{\mu\left[\gamma\left(\beta \varepsilon_{1}+\varepsilon_{2}\right)+\eta^{2} \varepsilon_{2}\right]^{2}\left(\alpha^{2} \beta^{2}+\mu\right)}{\left[\alpha^{2} \beta^{2} \gamma+\left(\eta^{2}+\gamma\right) \mu\right]^{2}} \\
L_{S}^{F}=\frac{\mu\left[\gamma\left(\beta \varepsilon_{1}+\varepsilon_{2}\right)+\eta^{2} \varepsilon_{2}\right]^{2}\left(\alpha^{2} \beta^{2}+\mu\right)+\gamma\left(\gamma+\eta^{2}\right)\left(\mu \varepsilon_{1}-\alpha^{2} \beta \varepsilon_{2}\right)}{\left[\alpha^{2} \beta^{2} \gamma+\left(\eta^{2}+\gamma\right) \mu\right]^{2}}
\end{gathered}
$$

\footnotetext{
${ }^{17}$ For sufficiently negative values of both shocks (or a combination thereof), the expression in (15) becomes negative. However, it would be natural to impose a non-negativity constraint on the nominal interest rate.
} 


\subsection{Case II: The government sets $f$ to minimise $L_{S}$}

Now the government is in charge of fiscal policy, and his behavior is described by (9). At the Nash equilibrium of the game, we have:

$$
\begin{aligned}
f^{N S} & =\frac{\eta\left[\beta\left(\alpha^{2}-\mu\right) \varepsilon_{2}-\mu\left(1+\beta^{2}\right) \varepsilon_{1}\right]}{\alpha^{2} \beta^{2} \gamma+\left[\eta^{2}\left(1+\beta^{2}\right)+\gamma\right] \mu} \\
i^{N S} & =\pi^{*}+\frac{\alpha \beta\left[\left(\eta^{2}+\gamma\right) \varepsilon_{2}+\beta \gamma \varepsilon_{1}\right]}{\alpha^{2} \beta^{2} \gamma+\left[\eta^{2}\left(1+\beta^{2}\right)+\gamma\right] \mu}
\end{aligned}
$$

yielding the following equilibrium losses:

$$
\begin{gathered}
L_{M}^{S}=\frac{\mu\left[\gamma\left(\beta \varepsilon_{1}+\varepsilon_{2}\right)+\eta^{2} \varepsilon_{2}\right]^{2}\left(\alpha^{2} \beta^{2}+\mu\right)}{\left[\alpha^{2} \beta^{2} \gamma+\left(\eta^{2}\left(1+\beta^{2}\right)+\gamma\right) \mu\right]^{2}} \\
L_{F}^{S}=\frac{\alpha^{2} \beta \gamma \varepsilon_{2}\left[\alpha^{2} \beta \varepsilon_{2}\left(\eta^{2}+\gamma\right)-2 \varepsilon_{1} \mu\left(\eta^{2}\left(1+\beta^{2}\right)+\gamma\right)\right]}{\left[\alpha^{2} \beta^{2} \gamma+\left(\eta^{2}\left(1+\beta^{2}\right)+\gamma\right) \mu\right]^{2}}+ \\
\frac{\mu^{2}\left\{\eta^{2}\left[\beta^{2}\left(\eta^{2} \varepsilon_{2}^{2}+\left(2 \varepsilon_{1}^{2}+\beta^{2} \varepsilon_{1}^{2}+2 \beta \varepsilon_{1} \varepsilon_{2}+\varepsilon_{2}^{2}\right) \gamma\right)+\varepsilon_{1}^{2} \gamma\right]+\varepsilon_{1}^{2} \gamma^{2}\right\}}{\left[\alpha^{2} \beta^{2} \gamma+\left(\eta^{2}\left(1+\beta^{2}\right)+\gamma\right) \mu\right]^{2}} \\
L_{S}^{S}=L_{F}^{S}+L_{M}^{S}
\end{gathered}
$$

In both cases, we note that both authorities react with a more restrictive policy setting (higher $i$, lower $f$ ) to a positive AD shock $\left(\varepsilon_{1}\right)$, whereas the response is different to positive AS shocks: again restrictive for the central bank, but instead expansive for the fiscal authority. Also note that the loss function of the central bank collapses to zero (bliss point) whenever $\mu=0$.

Now we compare the equilibrium loss which each authority obtains, when the fiscal authority is setting its instrument to minimize either $L_{F}$ or $L_{S}$. For the central bank, the comparison of eqs.(17) and (21) yields:

$$
L_{M}^{F}-L_{M}^{S}=\frac{\mu^{2} \beta^{2} \eta^{2}\left[\gamma\left(\beta \varepsilon_{1}+\varepsilon_{2}\right)+\eta^{2} \varepsilon_{2}\right]^{2}\left(\alpha^{2} \beta^{2}+\mu\right)\left[2 \alpha^{2} \beta^{2} \gamma+\mu\left(\eta^{2}\left(2+\beta^{2}\right)+2 \gamma\right)\right]}{\left[\alpha^{2} \beta^{2} \gamma+\mu\left(\eta^{2}+\gamma\right)\right]^{2}\left[\alpha^{2} \beta^{2} \gamma+\left(\eta^{2}\left(1+\beta^{2}\right)+\gamma\right) \mu\right]^{2}}
$$

Expression (24) suffices to prove the following result: 
Lemma 2 Since $L_{M}^{F}-L_{M}^{S}>0$ for all $\mu>0$, the central bank prefers the government to set its policy according to the minimization of $L_{S}$.

This result is intuitive, since if the government controls $f$, it shares part of the same burden of the central bank, and thus the central bank may use less intensely its policy instrument. In fact, we may also note from equation (24) that when the monetary policy instrument is costless $(\mu>0)$, then the central bank is indifferent to what the fiscal authority does.

For fiscal authorities, results are not quite as clear-cut. In general, we want to answer the following question: if the government wants to minimize $L_{S}$, should it then set its policy instrument, $f$, directly, or delegate its control to the treasury?

To proceed, let us first compare the two cases of eqs. (16) and (22). Consider the preferences of the treasury as to who must be in charge of settin $f$ so as to obtain the minimum value of $L_{F}$ :

$$
L_{F}^{F}-L_{F}^{S}<0 \text { for all } \varepsilon_{2} \in\left(\min \left\{\varepsilon_{2 a}, \varepsilon_{2 b}\right\}, \max \left\{\varepsilon_{2 a}, \varepsilon_{2 b}\right\}\right)
$$

and conversely it is instead preferable to set $f$ according to the minimization of $L_{S}$ outside the range: $\left(\min \left\{\varepsilon_{2 a}, \varepsilon_{2 b}\right\}, \max \left\{\varepsilon_{2 a}, \varepsilon_{2 b}\right\}\right)$, where:

$$
\begin{gathered}
\varepsilon_{2 a}=-\frac{\beta \gamma \varepsilon_{1}}{\eta^{2}+\gamma} \\
\varepsilon_{2 b}=\frac{\beta \gamma \mu \varepsilon_{1}\left[\alpha^{2} \beta^{2}\left(\alpha^{2} \gamma\left(2+\beta^{2}\right)+\left(\eta^{2}+1\right) 2 \mu\right)\right]+\mu\left[\left(2 \alpha^{2}+\mu\right)\left(\eta^{2}+\gamma\right)\right]}{\alpha^{2} \beta^{2}\left[\alpha^{2} \gamma\left(2 \alpha^{2} \beta^{2} \gamma+2 \mu\left(\eta^{2}+\gamma\right)+\beta^{2} \mu\left(\eta^{2}-\gamma\right)\right)-2 \gamma^{2} \mu^{2}\left(1+\eta^{2}\right)\right]}
\end{gathered}
$$

Second, comparing the two cases of eqs.(18)and (23) reveals that there exists a range of parameter values for which, assuming instead that the government controls $f$ to minimize $L_{S}$, it is preferable to delegate the control of $f$ to the treasury who will then minimise $L_{F}$ :

$$
L_{S}^{F}-L_{S}^{S}<0 \text { for all } \varepsilon_{2} \in\left(\min \left\{\varepsilon_{2 c}, \varepsilon_{2 d}\right\}, \max \left\{\varepsilon_{2 c}, \varepsilon_{2 d}\right\}\right)
$$

and conversely it is instead preferable to set $f$ according to the minimization of $L_{S}$ outside the range $\left(\min \left\{\varepsilon_{2 c}, \varepsilon_{2 d}\right\}, \max \left\{\varepsilon_{2 c}, \varepsilon_{2 d}\right\}\right)$, where:

$$
\varepsilon_{2 c}=\varepsilon_{2 a}=-\frac{\beta \gamma \varepsilon_{1}}{\eta^{2}+\gamma}
$$


$\varepsilon_{2 d}=\frac{\beta \gamma \mu \varepsilon_{1}\left[\alpha^{2}\left(\alpha^{2} \beta^{2} \gamma\left(2+\beta^{2}\right)+\left(\left(2-\beta^{2}\right) \eta^{2}+2 \gamma\left(1-\beta^{2}\right)\right) \mu\right)-\mu^{2}\left(\gamma+\eta^{2}\left(1+\beta^{2}\right)\right)\right]}{\Psi}$,

where:

$$
\begin{aligned}
\Psi= & \left(\eta^{2}+\gamma\right)\left[\gamma+\eta^{2}\left(1+\beta^{2}\right)\right] \mu^{3}+\alpha^{2} \beta^{2}\left\{2 \alpha^{4} \beta^{2} \gamma^{2}+\mu\left[\eta ^ { 2 } \left(\alpha^{2} \gamma\left(2+3 \beta^{2}\right)+\right.\right.\right. \\
& \left.\left.\left.\mu\left(\left(2+\beta^{2}\right) \eta^{2}+\gamma\left(4+\beta^{2}\right)\right)\right)+\gamma^{2}\left(2 \alpha^{2}+\alpha^{2} \beta^{2}+2 \mu\right)\right]\right\}
\end{aligned}
$$

The comparison between $\varepsilon_{2 b}$ and $\varepsilon_{2 d}$ reveals that

$$
\varepsilon_{2 d}>\varepsilon_{2 b} \text { for all } \varepsilon_{1}>0
$$

and conversely. This holds for all $\mu>0$. When $\mu=0, \varepsilon_{2 d}=\varepsilon_{2 b}=0$. We have thus proved the following:

Proposition 1 Assume $\mu>0$. Then for all $\varepsilon_{2} \in\left(\min \left\{\varepsilon_{2 b}, \varepsilon_{2 d}\right\}, \max \left\{\varepsilon_{2 b}, \varepsilon_{2 d}\right\}\right)$, the government prefers to delegate the control of fiscal policy to the treasury.

Notice that $\min \left\{\varepsilon_{2 b}, \varepsilon_{2 d}\right\}=\varepsilon_{2 b}$ for all $\varepsilon_{1}>0$, and conversely. This implies that (taking as an example a situation when there is a positive shock to $\mathrm{AD}$, i.e. $\left.\varepsilon_{1}>0\right)$, Proposition 1 identifies a range of $A S\left(\varepsilon_{2}\right)$ shocks for which the government is better off having delegated the control over fiscal policy, even if, in fact, it cares about the loss function $L_{S}$. The reason for this puzzling result is that the government must take into account also the policy choice of the central bank, which is also optimising $L_{M} \subset L_{S}$. However, this incentive to delegate disappears when $\mu=0$, since in this case the government is always better off by fully internalising the behaviour of the central bank. Graphically, as $\mu$ decreases towards zero, both $\varepsilon_{2 b}$ and $\varepsilon_{2 d}$ rotates downwards at different speeds. They coincide at $\mu=0$. This situation is shown in Figure 2 , where we assume $\mu>0$, so that $\varepsilon_{2 d} \gtreqless \varepsilon_{2 b}$ for all $\varepsilon_{1} \gtreqless 0$. 
Figure 2 : $\quad$ Socially harmful fiscal deviations

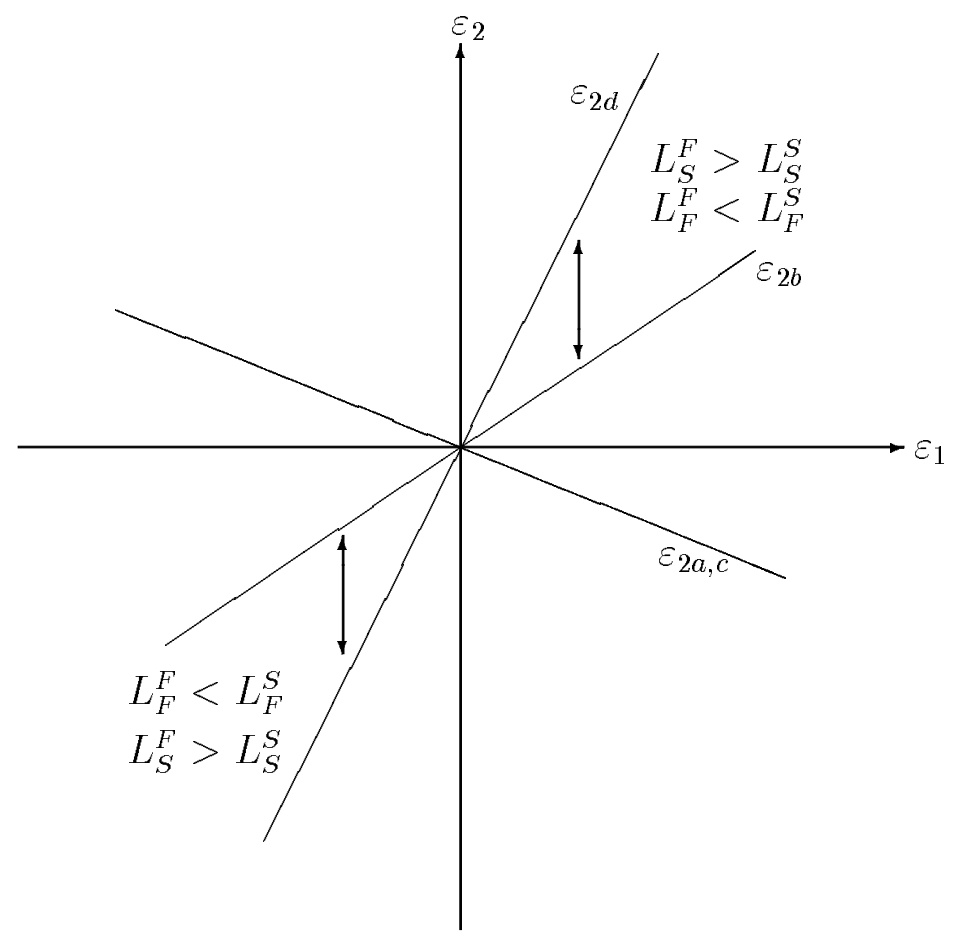

\section{The Stackelberg equilibrium with the bank as the follower}

Here we consider the case where the fiscal authority minimises her loss function under the constraint given by the central bank's best reply function (7). We analyse first the case where the government delegates fiscal policy to the treasury minister.

\subsection{The treasury takes the lead}

The leader's problem is:

$$
\begin{aligned}
\max L_{F} & =\left(y-y^{*}\right)^{2}+\gamma f^{2} \\
\text { s.t. } & : \quad i=\bar{r}+\pi^{*}+\frac{\alpha \beta}{\alpha^{2} \beta^{2}+\mu}\left[\beta\left(\eta f+\varepsilon_{1}\right)+\varepsilon_{2}\right]
\end{aligned}
$$


Proceeding by substitution, the objective function (27) can be differentiated with respect to $f$, to obtain the leader's first order condition:

$$
\frac{\partial L_{F}}{\partial f}=\frac{2 \eta \mu\left[\mu\left(\eta f+\varepsilon_{1}\right)-\alpha^{2} \beta \varepsilon_{2}\right]}{\left[\alpha^{2} \beta^{2}+\mu\right]^{2}}+2 \gamma f=0
$$

yielding:

$$
f^{t}=\frac{\eta \mu\left(\alpha^{2} \beta \varepsilon_{2}-\mu \varepsilon_{1}\right)}{\alpha^{2} \beta^{2} \gamma\left(\alpha^{2} \beta^{2}+2 \mu\right)+\mu^{2}\left(\eta^{2}+\gamma\right)}
$$

where superscript $t$ indicates that the Treasury is leading. Loss functions at equilibrium are:

$$
\begin{gathered}
L_{F}^{t}=\frac{\gamma\left(\mu \varepsilon_{1}-\alpha^{2} \beta \varepsilon_{2}\right)^{2}}{\alpha^{2} \beta^{2} \gamma\left(\alpha^{2} \beta^{2}+2 \mu\right)+\mu^{2}\left(\eta^{2}+\gamma\right)} \\
L_{M}^{t}=\frac{\mu\left(\alpha^{2} \beta^{2}+\mu\right)\left[\alpha^{2} \beta^{2} \gamma\left(\beta \varepsilon_{1}+\varepsilon_{2}\right)+\mu\left(\gamma\left(\beta \varepsilon_{1}+\varepsilon_{2}\right)+\eta^{2} \varepsilon_{2}\right)\right]}{\left[\alpha^{2} \beta^{2} \gamma\left(\alpha^{2} \beta^{2}+2 \mu\right)+\mu^{2}\left(\eta^{2}+\gamma\right)\right]^{2}}
\end{gathered}
$$

Accordingly, the loss of the government is $L_{S}^{t}=L_{F}^{t}+L_{M}^{t}$.

\subsection{The government takes the lead}

If the government sets fiscal policy so as to maximise social welfare in a Stackelberg setting where the bank follows, the leader's problem is:

$$
\begin{aligned}
\max L_{S} & =L_{F}+L_{M} \\
\text { s.t. } & : \quad i=\bar{r}+\pi^{*}+\frac{\alpha \beta}{\alpha^{2} \beta^{2}+\mu}\left[\beta\left(\eta f+\varepsilon_{1}\right)+\varepsilon_{2}\right]
\end{aligned}
$$

The optimal behaviour of the government is described by:

$$
\frac{\partial L_{S}}{\partial f}=\frac{2 \eta \mu\left[\beta\left(\alpha^{2} \beta+\mu\right)\left(\beta\left(\eta f+\varepsilon_{1}\right)+\varepsilon_{2}\right)+\mu\left(\eta f+\varepsilon_{1}\right)-\alpha^{2} \beta \varepsilon_{2}\right]}{\left(\alpha^{2} \beta^{2}+\mu\right)^{2}}+2 \gamma f=0
$$

which entails:

$$
f^{g}=-\frac{\eta \mu\left[\alpha^{2} \beta\left(\beta^{3} \varepsilon_{1}+\varepsilon_{2}\left(\beta^{2}-1\right)\right)+\mu\left(\varepsilon_{1}\left(1+\beta^{2}\right)+\beta \varepsilon_{2}\right)\right]}{\alpha^{2} \beta^{2}\left[\gamma\left(\alpha^{2} \beta^{2}+2 \mu\right)+\beta^{2} \eta^{2} \mu\right]+\mu^{2}\left[\eta^{2}\left(1+\beta^{2}\right)+\gamma\right]}
$$


where superscript $g$ indicates that the government is leading. The loss of the treasury is:

$$
\begin{aligned}
L_{F}^{g}= & \frac{\eta^{2} \gamma \mu^{2}\left[\alpha^{2} \beta\left(\beta^{3} \varepsilon_{1}+\varepsilon_{2}\left(\beta^{2}-1\right)\right)+\mu\left(\varepsilon_{1}\left(1+\beta^{2}\right)+\beta \varepsilon_{2}\right)\right]^{2}}{\left\{\alpha^{2} \beta^{2}\left[\gamma\left(\alpha^{2} \beta^{2}+2 \mu\right)+\beta^{2} \eta^{2} \mu\right]+\mu^{2}\left[\eta^{2}\left(1+\beta^{2}\right)+\gamma\right]\right\}^{2}}+ \\
& \frac{\left(\alpha^{2} \beta^{2}+\mu\right)^{2}\left[\gamma \mu \varepsilon_{1}-\beta \varepsilon_{2}\left(\alpha^{2} \gamma+\eta^{2} \mu\right)\right]^{2}}{\left\{\alpha^{2} \beta^{2}\left[\gamma\left(\alpha^{2} \beta^{2}+2 \mu\right)+\beta^{2} \eta^{2} \mu\right]+\mu^{2}\left[\eta^{2}\left(1+\beta^{2}\right)+\gamma\right]\right\}^{2}}
\end{aligned}
$$

while the loss of the central bank amounts to:

$$
L_{M}^{g}=\frac{\mu\left(\alpha^{2} \beta^{2}+\mu\right)\left[\left(\alpha^{2} \beta^{2}+\mu\right) \gamma\left(\beta \varepsilon_{1}+\varepsilon_{2}\right)+\mu \eta^{2} \varepsilon_{2}\right]}{\left\{\alpha^{2} \beta^{2}\left[\gamma\left(\alpha^{2} \beta^{2}+2 \mu\right)+\beta^{2} \eta^{2} \mu\right]+\mu^{2}\left[\eta^{2}\left(1+\beta^{2}\right)+\gamma\right]\right\}^{2}}
$$

and the social loss is $L_{S}^{g}=L_{F}^{g}+L_{M}^{g}$.

Now, comparing $L_{S}^{g}$ against $L_{S}^{t}$, we obtain the following expression:

$L_{S}^{g}-L_{S}^{t}=-\frac{\beta^{2} \eta^{2} \mu^{2}\left(\alpha^{2} \beta^{2}+\mu\right)^{2}\left[\alpha^{2} \beta^{2} \gamma\left(\beta \varepsilon_{1}+\varepsilon_{2}\right)+\mu\left(\varepsilon_{2}\left(\eta^{2}+\gamma\right)+\beta \gamma \varepsilon_{1}\right)\right]^{2}}{\Omega}$

where:

$$
\begin{aligned}
\Omega \equiv & {\left[\alpha^{2} \beta^{2} \gamma\left(\alpha^{2} \beta^{2}+2 \mu\right)+\mu^{2}\left(\eta^{2}+\gamma\right)\right]^{2}\left[\alpha^{2} \beta^{2}\left(\alpha^{2} \beta^{2} \gamma+2 \mu \gamma+\beta^{2} \eta^{2} \mu\right)\right.} \\
& \left.+\mu^{2}\left(\gamma+\eta^{2}\left(1+\beta^{2}\right)\right)\right]
\end{aligned}
$$

which reveals that $L_{S}^{g}<L_{S}^{t}$ always. Therefore, the following result holds:

Lemma 3 Since $L_{S}^{g}<L_{S}^{t}$ holds for all admissible values of parameters and shocks, the government always prefers to set the fiscal policy according to the maximisation of social welfare.

Now, evaluating $L_{M}^{g}$ and $L_{M}^{t}$, we have $L_{M}^{g}<L_{M}^{t}$ always. Hence, we can state:

Lemma 4 Since $L_{M}^{g}<L_{M}^{t}$ holds for all admissible values of parameters and shocks, the central bank always prefers when the government sets fiscal policy according to the social welfare function.

Lemmata 3-4 entail the following Proposition: 
Proposition 2 When the government sets fiscal policy as the leader, the incentives of the fiscal authority and the monetary authority are reciprocally compatible.

When the government sets fiscal policy as the leader, it is in the position of fully internalising the monetary target. This obviously goes some way towards reducing the burden of stabilization left for the central bank. To check this, it suffices to verify that $i^{g}<i^{t}$ over the whole admissible space of parameters.

\section{The central bank takes the lead}

Here, we consider the case where the central bank chooses the interest rate before the fiscal authority decides the size of $f$. Again, we have two cases: one is the situation where fiscal policy is set by the treasury, taking into account its loss function $L_{F}$; the other is the situation where the government sets fiscal policy so as to maximise social welfare $L_{S}=L_{F}+L_{M}$.

\subsection{Case I: The treasury controls fiscal policy}

The treasury plays the follower's role by minimising $L_{F}$ w.r.t. $f$, taking the interest rate as given. This produces the following reaction function:

$$
\frac{\partial L_{F}}{\partial f}=\left(\eta^{2}+\gamma\right) f+\eta\left[\varepsilon_{1}-\alpha\left(i-\pi^{*}\right)\right]=0 .
$$

The problem of the central bank is:

$$
\begin{aligned}
\max _{i} L_{M} & =\left[\varepsilon_{2}+\beta\left(\varepsilon_{1}+\eta f-\alpha\left(i-\pi^{*}\right)\right)\right]^{2}+\mu\left(i-\pi^{*}\right)^{2} \\
\text { s.t. } & : \quad f=-\frac{\eta\left[\varepsilon_{1}-\alpha\left(i-\pi^{*}\right)\right]}{\eta^{2}+\gamma}
\end{aligned}
$$

The first order condition is:

$$
\frac{\partial L_{M}}{\partial i}=\frac{2 \alpha \beta \gamma\left[\alpha \beta \gamma\left(i-\pi^{*}\right)-\varepsilon_{2}\left(\eta^{2}+\gamma\right)-\beta \gamma \varepsilon_{1}\right]}{\left(\eta^{2}+\gamma\right)^{2}}+2 \mu\left(i-\pi^{*}\right)^{2}=0
$$

yielding the following optimal interest rate:

$$
i_{T}^{b}=\frac{\alpha \beta \gamma\left[\varepsilon_{2}\left(\eta^{2}+\gamma\right)+\beta \gamma \varepsilon_{1}\right]}{\alpha^{2} \beta^{2} \gamma^{2}+\mu\left(\eta^{2}+\gamma\right)^{2}}+\pi^{*},
$$


where superscript $b$ indicates that the bank is leading, and subscript $T$ indicates that fiscal policy is set by the treasury. The resulting loss functions are:

$$
\begin{gathered}
L_{M T}^{b}=\frac{\mu\left[\gamma\left(\beta \varepsilon_{1}+\varepsilon_{2}\right)+\eta^{2} \varepsilon_{2}\right]^{2}}{\alpha^{2} \beta^{2} \gamma^{2}+\mu\left(\eta^{2}+\gamma\right)^{2}} \\
L_{F T}^{b}=\frac{\gamma\left(\eta^{2}+\gamma\right)\left[\mu \varepsilon_{1}\left(\eta^{2}+\gamma\right)-\alpha^{2} \beta \gamma \varepsilon_{2}\right]^{2}}{\left[\alpha^{2} \beta^{2} \gamma^{2}+\mu\left(\eta^{2}+\gamma\right)^{2}\right]^{2}}
\end{gathered}
$$

and social welfare $L_{S T}^{b}=L_{F T}^{b}+L_{M T}^{b}$.

\subsection{Case II: The government controls fiscal policy}

Here, the government plays the follower's role by minimising $L_{S}$ w.r.t. $f$, taking the interest rate as given. This produces the following reaction function:

$\frac{\partial L_{F}}{\partial f}=\left(\eta^{2}+\gamma\right) f+\eta\left[\varepsilon_{1}-\alpha\left(i-\pi^{*}\right)\right]+2 \beta \eta\left[\varepsilon_{2}+\beta\left(\varepsilon_{1}+\eta f-\alpha\left(i-\pi^{*}\right)\right)\right]=0$.

The problem of the central bank is:

$$
\begin{aligned}
\max _{i} L_{M} & =\left[\varepsilon_{2}+\beta\left(\varepsilon_{1}+\eta f-\alpha\left(i-\pi^{*}\right)\right)\right]^{2}+\mu\left(i-\pi^{*}\right)^{2} \\
\text { s.t. } & : f=-\frac{\eta\left[\varepsilon_{1}\left(1+\beta^{2}\right)+\beta \varepsilon_{2}-\alpha\left(1+\beta^{2}\right)\left(i-\pi^{*}\right)\right]}{\eta^{2}\left(1+\beta^{2}\right)+\gamma}
\end{aligned}
$$

$>$ From the first order condition we obtain the optimal interest rate:

$$
i_{G}^{b}=\frac{\alpha \beta \gamma\left[\varepsilon_{2}\left(\eta^{2}+\gamma\right)+\beta \gamma \varepsilon_{1}\right]}{\alpha^{2} \beta^{2} \gamma^{2}+\mu\left[\eta^{2}\left(1+\beta^{2}\right)\left(\eta^{2}\left(1+\beta^{2}\right)+2 \gamma\right)+\gamma^{2}\right]}+\pi^{*},
$$

where subscript $G$ indicates that fiscal policy is set by the government. The associated loss of the central bank is:

$$
L_{M G}^{b}=\frac{\mu\left[\varepsilon_{2}\left(\eta^{2}+\gamma\right)+\beta \gamma \varepsilon_{1}\right]^{2}}{\alpha^{2} \beta^{2} \gamma^{2}+\mu\left[\eta^{2}\left(1+\beta^{2}\right)\left(\eta^{2}\left(1+\beta^{2}\right)+2 \gamma\right)+\gamma^{2}\right]} .
$$

The loss of the treasury is:

$$
L_{F G}^{b}=\frac{\eta^{2} \gamma\left[\mu\left(1+\beta^{2}\right)\left(\varepsilon_{1}\left(\eta^{2}\left(1+\beta^{2}\right)+\gamma\right)+\beta \eta^{2} \varepsilon_{2}\right)-\alpha^{2} \beta \gamma \varepsilon_{2}\right]^{2}}{\Gamma}+
$$




$$
\frac{\left[\mu\left(\eta^{2}\left(\gamma \varepsilon_{1}-\beta \eta^{2} \varepsilon_{2}\right)\left(1+\beta^{2}\right)+\gamma\left(\gamma \varepsilon_{1}-\beta \eta^{2} \varepsilon_{2}\right)\right)-\alpha^{2} \beta \gamma^{2} \varepsilon_{2}\right]^{2}}{\Gamma}
$$

where

$$
\Gamma=\left[\alpha^{2} \beta^{2} \gamma^{2}+\mu\left[\eta^{2}\left(1+\beta^{2}\right)\left(\eta^{2}\left(1+\beta^{2}\right)+2 \gamma\right)+\gamma^{2}\right]\right]^{2} .
$$

The resulting social loss is $L_{S G}^{b}=L_{F G}^{b}+L_{M G}^{b}$.

\subsection{The follower's choice}

Here, we want to assess whether the government finds it convenient to set fiscal policy so as to maximise social welfare or allowing the treasury to manoeuvre the budget.

First, comparing the levels of $L_{M}$ in the two cases, we have:

Lemma 5 Since $L_{M G}^{b}<L_{M T}^{b}$ for all values of parameters and shocks, the central bank prefers the government to set fiscal policy so as to maximise social welfare.

Then, note that

$$
i_{G}^{b}-i_{T}^{b} \propto-\left[\beta \gamma \varepsilon_{1}+\varepsilon_{2}\left(\eta^{2}+\gamma\right)\right]
$$

i.e., if both shocks are positive, $i_{G}^{b}<i_{T}^{b}$; if both shocks are negative, $i_{G}^{b}>i_{T}^{b}$. If instead shocks have opposite signs, then things can go either way. This entails that, when the bank leads, the government will not necessarily choose to support or contrast its policy stance. The ultimate implication of the above inequality is that the government will surely prefer the treasury to set $f$ in some region of $\left\{\varepsilon_{1}, \varepsilon_{2}\right\}$. For future reference, note that

$$
i_{G}^{b}=i_{T}^{b} \text { at } \varepsilon_{2}=-\frac{\beta \gamma \varepsilon_{1}}{\eta^{2}+\gamma} .
$$

Now compare $L_{S G}^{b}$ and $L_{S T}^{b}$. They coincide at

$$
\begin{gathered}
\varepsilon_{2 m}=-\frac{\beta \gamma \varepsilon_{1}}{\eta^{2}+\gamma} \\
\varepsilon_{2 n}=\gamma \mu \varepsilon_{1}\left[\gamma^{3}\left(3 \gamma^{2}+14 \gamma+15\right)+\gamma \mu\left(2 \gamma^{4}+18 \gamma^{3}+50 \gamma^{2}+57 \gamma+24\right)+\right. \\
\left.-\mu^{2}\left(8+\gamma\left(\gamma^{4}+8 \gamma^{3}+25 \gamma^{2}+38 \gamma+28\right)\right)\right] /\left[2 \gamma^{5}(3+2 \gamma)+\gamma^{2} \mu(15 \gamma+\right. \\
\left.27 \gamma^{2}+19 \gamma^{3}+5 \gamma^{4}+\left(7+19 \gamma+20 \gamma^{2}+10 \gamma^{3}+2 \gamma^{4}\right) \mu\right)+\mu^{3}(8+ \\
\left.\left.\gamma\left(36+66 \gamma+63 \gamma^{2}+33 \gamma^{3}+9 \gamma^{4}+\gamma^{5}\right)\right)\right] .
\end{gathered}
$$

Fxamining the sign of $L_{S G}^{b}-L_{S T}^{b}$, we have the following: 
Lemma $6 L_{S G}^{b}-L_{S T}^{b}>0$ for all $\varepsilon_{2} \in\left(\min \left\{\varepsilon_{2 m}, \varepsilon_{2 n}\right\}, \max \left\{\varepsilon_{2 m}, \varepsilon_{2 n}\right\}\right)$, and conversely outside this interval.

Then, examine the preferences of the treasury. We have $L_{F G}^{b}=L_{F T}^{b}$ at:

$$
\varepsilon_{2 o}=-\frac{\beta \gamma \varepsilon_{1}}{\eta^{2}+\gamma} ; \varepsilon_{2 p}=\bar{\varepsilon}_{2 p}
$$

where the expression of $\bar{\varepsilon}_{2 p}$ is too long to be printed and, in general, for positive values of $\varepsilon_{1}, \bar{\varepsilon}_{2 p}>\varepsilon_{2 n}$ for sufficiently high values of the ratio $\gamma / \mu$, while $\bar{\varepsilon}_{2 p}<\varepsilon_{2 n}$ for sufficiently low values of the ratio $\gamma / \mu$. The opposite holds for negative values of $\varepsilon_{1}$.

The preferences of the treasury on the objective of fiscal policy are described by the sign of $L_{F G}^{b}-L_{F T}^{b}$. Given the roots $\varepsilon_{2 o}$ and $\varepsilon_{2 p}$, its preferences are summarised by the following Lemma:

Lemma $7 L_{F G}^{b}-L_{F T}^{b}>0$ for all $\varepsilon_{2} \in\left(\min \left\{\varepsilon_{2 o}, \varepsilon_{2 p}\right\}, \max \left\{\varepsilon_{2 o}, \varepsilon_{2 p}\right\}\right)$, and conversely outside this interval.

On the basis of Lemmata 6-7, we can claim the following:

Proposition 3 When the central bank leads, there are shock configurations such that the government may want to delegate control over fiscal policy to the treasury.

We can outline graphically the region of shocks where there exists a conflict between the treasury and the government as to who has to be in charge of fiscal policy.

When $\gamma / \mu$ is large enough, $\bar{\varepsilon}_{2 p}>\varepsilon_{2 n}$ for positive $\varepsilon_{1}$ and $\bar{\varepsilon}_{2 p}<\varepsilon_{2 n}$ for negative $\varepsilon_{1}$. Therefore:

$$
\text { for all } \varepsilon_{2} \in\left(\min \left\{\varepsilon_{2 n}, \varepsilon_{2 p}\right\}, \max \left\{\varepsilon_{2 n}, \varepsilon_{2 p}\right\}\right) \text {, }
$$

both authorities would like to set the fiscal policy.

Conversely, if $\gamma / \mu$ is low enough, $\bar{\varepsilon}_{2 p}<\varepsilon_{2 n}$ for positive $\varepsilon_{1}$ and $\bar{\varepsilon}_{2 p}>\varepsilon_{2 n}$ for negative $\varepsilon_{1}$. Therefore, for all $\varepsilon_{2} \in\left(\min \left\{\varepsilon_{2 n}, \varepsilon_{2 p}\right\}, \max \left\{\varepsilon_{2 n}, \varepsilon_{2 p}\right\}\right)$, both authorities would like that the other sets fiscal policy. 


\section{$7 \quad$ Equilibrium selection}

As we have illustrated in section 3, relying upon d'Aspremont and GérardVaret (1980) and Hamilton and Slutsky (1990), we can select between Nash and Stackelberg equilibria. The selection mechanism is based on the slope of reaction functions, which are everywhere increasing. Therefore, both Stackelberg equilibria Pareto-dominate the Nash equilibrium. Moreover, if there exists a preplay stage where players non-cooperatively and simultaneously choose the timing of their moves, both Stackelberg equilibria are Nash equilibria of such preplay stage.

The next question is how to identify which will be selected, among the multiplicity of Stackelberg equilibria (two in pure strategies and one in mixed strategy). While formally they are all plausible outcomes, in practice two independent factors point to the fiscal authority becoming the Stackelberg leader. First, this is the outcome which minimizes frictions within the government and between the central bank and the government. As we noted above (Proposition 3), if the central bank leads, then there are shock configurations where the government might want to set fiscal policy according to the minimization of $\mathrm{L}_{F}$, without taking into account the inflation objective. This would create confusion between the different levels of government (why is the government switching between different obiective functions at different times?), and also in the face of the central bank and of course of the public opinion. This confusion would be further aggravated in a monetary union such as EMU, because it would imply switching the decision level of fiscal policy back and forth between the EC and the national authorities.

The second reason for the fiscal authority to become the Stackelberg leader is inherent to the institutional process. Since the leader commits to the first move, it would be highly implausible if this were the central bank, as the decision to fix ex-ante and once-and-for-all the interest rate level would be unprecedented! Quite to the contrary, in practice we observe that fiscal policy is generally set prior to monetary policy, and revised much less frequently. Typically, fiscal policy is set once a year, whereas monetary policy is usually revised, both in EMU and in the US, every two weeks. This situation is interpretable as one where the fiscal authority is the first mover, i.e. the Stackelberg leader. As we noted in the previous section (Lemma 3), in this case there would also be no doubt as to the choice of the appropriate objective function, nor would the central bank ever want to question the stance adopted by the fiscal policy (Lemma 4). 
Hence, on the basis of the above reasoning, we conclude that it is both preferable and quite probable that the fiscal authority will in practice emerge as the Stackelberg leader in the macroeconomic policy game.

\section{Discussion}

In this paper we have examined the interrelations between monetary and fiscal policies, in a game situation where both policies are set consistently over time and with each other, and both policy instruments are costly to operate. This implies that there are costs associated to changes in the (real) interest rate and also to non-zero budget levels. The latter cost is modelled after the requirement of the Stability and Growth Pact, that budget levels should be balanced over the medium term.

We also assumed that the government is motivated by the minimization of a welfare function defined in terms of output and inflation deviations from their natural or target levels, and delegates the "inflation subset" of this function to the central bank. This assumption mirrors the constitutional mandate of the ECB towards maintaining price stability. However, this also leads to an interesting question: having delegated to an independent agent (the ECB) part of its welfare function, should the government then set its own policy instrument (the fiscal stance) according to the overall welfare criterion or only to that part which has not been delegated to the ECB? In the paper we refer to these alternatives respectively as the "government view" (whereby fiscal policy is set to minimize $\mathrm{L}_{S}$ ) and the "treasury view" (whereby fiscal policy is set to minimize $\mathrm{L}_{F}$ ).

The analysis of alternative game situations suggests that both fiscal and monetary authorities prefer the outcome of a Stackelberg to that of a Nash game, independently of whom is the leader. However, the nature of the game is such that, if asked, each player would leave to the other the disadvantage of the first move. In our context, this is quite intuitive: since the two authorities place different but non-conflicting weights on the welfare goals, each one would prefer to be the last one to move, to turn the overall result in the preferred direction. This raises the question of which particular Stackelberg solution will then emerge in practice.

In this respect we argued in the previous section that in practice two independent factors point to the fiscal authority becoming the Stackelberg leader. The first reason is that, if this were not the case, then depending on 
specific shock configurations the government might want to set fiscal policy either according to the minimization of $\mathrm{L}_{\mathrm{F}}$ (that is, without taking into account the inflation objective) or of $\mathrm{L}_{\mathrm{S}}$. This would create confusion between the different levels of government (why is the government switching between different obiective functions at different times?), and also in the face of the central bank and of course of the public opinion. This confusion would be further aggravated in a monetary union such as EMU, because it would imply switching the decision level of fiscal policy back and forth between the EC and the national authorities.

The second reason for the fiscal authority to become the Stackelberg leader is imbedded into the institutional process. In practice we always observe that fiscal policy is set prior to monetary policy, and revised much less frequently. Typically, fiscal policy is set once a year, whereas monetary policy is usually revised, both in EMU and in the US, every two weeks. This situation is interpretable as one where the fiscal authority is the natural first mover, i.e. the Stackelberg leader.

Hence we may conclude that the fiscal authority will in practice emerge as the Stackelberg leader in the macroeconomic policy game, and that this situation is indeed desirable. Notice also that in this case, according to Lemma 2 the government will always want to set fiscal policy according to the minimization of $\mathrm{L}_{\mathrm{S}}$ (the all-inclusive social welfare function). In the context of EMU, this implies that the fiscal stance should not be decided looking only to the the stabilization of national output levels. In other words, this result points to the desirability of a coordination process of national fiscal policies, whereby they are set taking into account also the goal of monetary policy.

In the context of a monetary union with decentralized fiscal policies (as is the case of EMU) this distinction takes on an additional dimensionality, since the treasury view can naturally be attributed to national governments (which do not internalize the consequences of their actions for the union-wide rate of inflation), and the government view can naturally be attributed to the European Commission. In fact this situation is reflected, albeit imperfectly, into the existing institutional arrangements for policy coordination. In general terms, the Treaty Establishing the European Union states (Art. 99) the aim for a "closer coordination of economic policies and sustained convergence of the economic performances". To this purpose, the European Council is requested to formulate "broad guidelines of the economic policies of the Member States", to monitor economic developments in each of the Member States 
and, where necessary, to adopt recommendations to ensure consistency of national economic policies with the Community guidelines. The importance and implications of these additional provisions was probably not entirely clear at the outset of EMU, and both national governments and independent commentators initially discounted their importance. However, with the adoption of the Stability and Growth Pact (SGP) after 1997, it became apparent that the Broad Economic Policy Guidelines (BEPG) could in principle become quite important, especially in view of the additional goal, stated in the SGP, that national fiscal policies should aim for "the medium-term budgetary objective of close to balance or in surplus"18. Thus the current institutional setup requires the Commission to monitor the application of the SGP, and hence also to take into account the possible inflationary implications of the fiscal policies individually adopted by the national governments ${ }^{19}$. Hence, while we do not model explicitly the interaction between national authorities and the European Commission, our results may have some relevance also to this case, and they broadly support the case for EMU-wide coordination of national fiscal policies, to reduce the costs of monetary policy pursuing the goal of price stability.

\section{Appendix}

In this Appendix we show that if the loss function of the central bank includes a term in the output gap, monetary policy is bound to be time-inconsistent. Suppose the government sets $f$ to maximise $L_{S}$, while the central bank sets $i$ to minimise a loss function including a term in output stabilisation:

$$
L_{M 2} \equiv\left(\pi-\pi^{*}\right)^{2}+\left(y-y^{*}\right)^{2}+\mu(r-\bar{r})^{2} .
$$

Using (56), it can be shown that optimal monetary policy is bound to be time-inconsistent against the fiscal policy of the government, in the same sense as it would be time-inconsistent against the private sector in a model à la Kydland and Prescott (1977) or Barro and Gordon (1983).

To prove this, take the first order condition of the government; this yields

\footnotetext{
${ }^{18}$ As we remarked earlier on, the European Commission (2002b) has recently put forward some proposals to improve the application of existing rules of the SGP.

${ }^{19}$ The examples in footnote 4 show how this becomes relevant in practice.
} 
the following best reply function:

$$
f^{b r 2}=\frac{\eta\left[\alpha\left(1+\beta^{2}\right)\left(i-\pi^{*}\right)-\left(1+\beta^{2}\right) \varepsilon_{1}+\beta \varepsilon_{2}\right]}{\gamma+\eta^{2}\left(1+\beta^{2}\right)}
$$

Then, suppose the central bank announces that it will set $i$ so as to obtain $\pi=\pi^{*}$.From the AS curve we obtain the interest rate level ensuring that the targeted inflation rate is reached:

$$
i\left(\pi^{*}\right)=\frac{\beta\left(\alpha \pi^{*}+\eta f+\varepsilon_{1}\right)+\varepsilon_{2}}{\alpha \beta}
$$

Suppose the central bank announces that $i\left(\pi^{*}\right)$ will be implemented, and the government believes. If so, the associated fiscal stance is:

$$
f\left(i\left(\pi^{*}\right)\right)=\frac{\eta \varepsilon_{2}}{\beta \gamma}
$$

and (58) simplifies as follows:

$$
i\left(\pi^{*}\right)=\pi^{*}+\frac{\beta \gamma \varepsilon_{1}+\left(\eta^{2}+\gamma\right) \varepsilon_{2}}{\alpha \beta \gamma}
$$

Now, alternatively, one can solve $\partial L_{M 2} / \partial i=0$ to obtain the best reply of the central bank, where the fiscal stance of the government is given by (59). Here, the optimal interest rate is:

$$
i^{*}=\frac{\alpha\left[\varepsilon_{2}\left(\left(1+\beta^{2}\right) \eta^{2}+\beta^{2} \gamma\right)+\gamma \beta\left(1+\beta^{2}\right)\left(\alpha \pi^{*}+\varepsilon_{1}\right)\right]}{\beta \gamma\left[\left(1+\beta^{2}\right) \alpha^{2}+\mu\right]}
$$

which differs from $i\left(\pi^{*}\right)$ both ex ante and ex post.

\section{References}

[1] Alesina, A. and G. Tabellini (1987), "Rules and Discretion with Noncoordinated Monetary and Fiscal Policies", Economic Inquiry, 25, 619-630.

[2] Andersen, T. (2002), "Fiscal Stabilization Policy in a Monetary Union with Inflation Targeting", CEPR Discussion Paper no. 3232. 
[3] Beetsma, R. and A.L. Bovenberg (1999), "Does Monetary Unification Lead to Excessive Debt Accumulation?", Journal of Public Economics, $74,299-325$.

[4] Beetsma, R. and A.L. Bovenberg (2001), "Structural Distortions and Decentralized Fiscal Policies in EMU", CEPR Discussion Paper no. 2851.

[5] Beetsma, R., X. Debrun and F. Klaassen (2001), "Is Fiscal Policy Coordination in EMU Desirable?", CEPR Discussion Paper no. 3035.

[6] Beetsma, R. and H. Uhlig (1999), "An Analysis of the Stability and Growth Pact", The Economic Journal, 109, 546-571.

[7] Blinder, A.S. (1997) "Distinguished Lecture on Economics in Government: What Central Bankers Could Learn from Academics - and Vice Versa", Journal of Economic Perspectives, 11, 2, Spring, 3-19

[8] Brunila, A., M. Buti and J. in 'tVeld (2002) "Fiscal policy in Europe: how effective are automatic stabilisers?" European Commission - DG for Economic and Financial Affairs Economic Papers, No. 177, September.

[9] Bulow, J., J. Geanakoplos and P. Klemperer (1985), "Multimarket Oligopoly: Strategic Substitutes and Complements", Journal of Political Economy, 93, 488-511.

[10] Buti, M., W. Roeger and J. in't Veld (2001), "Stabilising Output and Inflation: Policy Conflicts and Co-operation under a Stability Pact", Journal of Common Market Studies, 39, 801-828.

[11] Canzoneri, M.B. and D.W. Henderson (1991), Monetary Policy in Interdependent Economies. A Game-Theoretic Approach, Cambridge, MA, MTT Press.

[12] Chari, V.V. and P.J. Kehoe (1999), "Optimal Fiscal and Monetary Policy", Handbook of Macroeconomics, North Holland, Vol.1c, Ch.26.

[13] d'Aspremont, C. and L.-A. Gérard-Varet (1980), "Stackelberg-Solvable Games and Pre-Play Communication", Journal of Economic Theory, 23, 201-217. 
[14] Debelle, G. and S. Fischer (1995) "How Independent Should a Central Bank Be?" In J.C. Fuhrer (ed.), Goals, Guidelines, and Constraints Facing Monetary Policymakers, Federal Reserve Bank of Boston, Conference Series No.38, 195-221.

[15] Dixit, A. and L. Lambertini (2001), "Monetary-Fiscal Policy Interactions and Commitment versus Discretion in a Monetary Union", European Economic Review, 45, 977-987.

[16] Dixit, A. and L. Lambertini (2002), "Fiscal Discretion Destroys Monetary Commitment", American Economic Review, forthcoming.

[17] European Commission (2002a), "Public Finances in EMU 2002", European Economy, no.3, 2002. Internet: http://europa.eu.int/comm/economy_finance/publications/european_economy/ 2002/ee302en.pdf

[18] European Commission (2002b) "Strenghtening the co-ordination of budgetary policies", Communication from the Commission to the Council and the European Parliamen, 21 November.

[19] Fatás, A. and I. Mihov (2001), "The Effects of Fiscal Policy on Consumption and Employment: Theory and Evidence", CEPR Discussion Paper no. 2760.

[20] Favero, C.A. and R. Rovelli (2003), "Macroeconomic Stability and the Preferences of the Fed. A Formal Analysis, 1961-98", Journal of Money, Credit and Banking, forthcoming.

[21] Hamada, K. (1976), "A Strategic Analysis of Monetary Interdependence", Journal of Political Economy, 84, 677-700.

[22] Hamilton, J.H. and S.M. Slutsky (1990), "Endogenous Timing in Duopoly Games: Stackelberg or Cournot Equilibria", Games and Economic Behavior, 2, 29-46.

[23] von Hagen, J. and S. Mundschenk (2001), " The political economy of policy coordination in the EMU", Swedish Economic Policy Review, 8, 107-137. (Internet: http://www.ekradet.konj.se/sepr/). 
[24] Lambertini, L. (1999), "The International Coordination of Monetary Policy: A Game-Theoretic Reformulation", Keio Economic Studies, 36, $39-49$.

[25] Lambertini, L. and R. Rovelli (2002), "Optimal Fiscal Stabilization Policy with Credible Central Bank Independence", working paper no., Department of Economics, University of Bologna.

[26] Lambertini, L. and R. Rovelli (2003), "Independent or Coordinated? Monetary and Fiscal Policy in EMU", in Beetsma et al. (eds), Fiscal Policies, Monetary Policies and Labour Markets: Key Aspects of European Macroeconomic Policies after Monetary Unification, Cambridge University Press, forthcoming.

[27] Leeper, E.M. (1991), "Equilibria Under Active and Passive Monetary and Fiscal Policy", Journal of Monetary Economics, 27, 129-147.

[28] Persson, T. and G. Tabellini (1993), "Designing Institutions for Monetary Stability", Carnegie-Rochester Conference Series on Public Policy, $39,53-84$

[29] Rogoff, K. (1987), "The Optimal degree of Committment to and Intermediate Monetary Target", Quarterly Journal of Economics, 100, 11691190.

[30] Sargent, T.J. and Wallace, N. (1981), "Some Unpleasant Monetarist Arithmetic", FRB of Minneapolis Quarterly Review, 5, no.3, 1-17.

[31] Svensson L. (1997), "Inflation Forecast Targeting: Implementing and Monitoring Inflation Targets", European Economic Review, 41, 11111146.

[32] Uhlig, H. (2002), "One Money, but Many Fiscal Policies in Europe: What Are the Consequences?", CEPR Discussion Paper no. 3296.

[33] Van Arle, B., J. Engwerda and J. Plasmans (2001), "Monetary and Fiscal Policy Interaction in the EMU: A Dynamic Game Approach", CESifo Working Paper no. 437.

[34] Walsh, C.E. (1995), "Optimal Contracts for Central Bankers", American Economic Review, 85, 150-167. 
[35] Walsh, C.E. (1998), Monetary Theory and Policy, Cambridge, MA, MIT Press.

[36] Woodford, M. (1995), "Price Level Determinacy Without Control of a Monetary Aggregate", Carnegie-Rochester Conference Series on Public Policy, 43, 1-46.

[37] Woodford, M.(1998),. "Control of the Public Debt: a Requirement for Price Stability?", In Calvo, G.A. and M. King (eds.), The Debt Burden and Its Consequences for Monetary Policy, IEA Conference Volume no.118, London, MacMillan. 